\title{
Coerência e responsabilidade política da decisão em Dworkin *
}

\author{
Recebido: 13 abril de 2018 • Aprovado: 26 de julho de 2018 \\ https://doi.org/10.22395/ojum.v18n36a4 \\ Jeferson Dytz Marin** \\ Nelson Gularte Ramos Neto**
}

\section{RESUMO}

A necessidade de elaborar uma teoria da decisão surge para o pós-positivismo como condição de sua existência. A indeterminação normativa, que, para o positivismo jurídico era sinônimo de liberdade no ato decisório, significa para o novo paradigma a premente busca pela legitimidade das decisões judiciais, haja vista que não há vinculação necessária entre imprecisão linguística e inexistência de resposta correta. Esta não pode ser entendida como uma mera decorrência lógica daquela, mas sim como uma opção que a teoria (positivista) do Direito toma para solução do "problema". A partir da teoria da decisão dworkiniana, constrói-se uma resposta correta não discricionária exigida pela noção de responsabilidade política do julgador. Entende-se que a proposta interpretativa de Ronald Dworkin pode ser erigida a um conceito geral de Direito como interpretação. À coerência com o passado —o sistema legislativo e as decisões judiciais — se soma a possibilidade de futura extensão a casos semelhantes, motivo pelo qual o princípio que se extrai da decisão deve também ser demonstrado como universalizável.

Palauras-chave: Dworkin; teoria da decisão; coerência; integridade; responsabilidade política.

\footnotetext{
Reflexão sobre a teoria da decisão judicial de Ronald Dworkin feita por membros do Projeto de Pesquisa Fundamentação das decisões no novo código de processo civil: superação da estandardização e os reflexos no Direito Ambiental, iniciado em 2016 e atualmente em andamento, vinculado ao Programa de Pós-Graduação em Direito da Universidade de Caxias do Sul, Brasil.

** Advogado, Universidade de Caxias do Sul, Caxias do Sul, Brasil. Especialização em Direito Processual, Universidade de Caxias do Sul, Caxias do Sul, Brasil. Mestrado em Direito, Universidade de Santa Cruz do Sul, Santa Cruz do Sul, Brasil. Doutorado em Direito, Universidade do Vale do Rio dos Sinos, São Leopoldo, Brasil. Professor da Pós-Graduação em Direito da UCS (Doutorado e Mestrado), Caxias do Sul, Brasil.E-mail: jeferson@marinadv.com.br

"** Procurador do Estado do Rio Grande do Sul, Universidade de Caxias do Sul, Caxias do Sul, Brasil. Mestrado em Direito, Universidade de Caxias do Sul, Caxias do Sul, Brasil. Pesquisador do Programa de Pós-Graduação em Direito da Universidade de Caxias do Sul, Brasil. E-mail: nelson-neto@pge.rs.gov.br
} 


\title{
Coherence and Political Responsibility of the Decision in Dworkin
}

\begin{abstract}
The need to formulate a Decision Theory arises for Postpositivism as a condition of its existence. The normative indeterminacy, whereas legal positivism was a synonymous of freedom in decision-making act, means to the new paradigm the urgent quest for legitimacy of judgments, since there is no linking required between linguistic vagueness and lack of correct answer. This lackness cannot be understood as a merely logical consequence of the linguistic vagueness, but as an option that the (Positivistic) Law Theory takes to solve the "problem". From the dworkinian Decision Theory it was built a correct and not discretionary answer required by the notion of political responsibility of the judge. It is understood that Ronald Dworkin's proposal can be erected to a general concept of law as interpretation. In consistency with the past, the legislative system and the judicial decisions add the possibility of future extension to similar cases, which is why the principle that is taking from the decision should also be shown as universalizing.
\end{abstract} Keywords: Dworkin; decision theory; coherence; integrity; political responsibility.

\section{Coherencia y responsabilidad políica de la decisión en Dworkin}

\section{RESUMEN}

La necesidad de elaborar una teoría de la decisión surge para el post-positivismo como condición de su existencia. La indeterminación normativa, que para el positivismo jurídico era sinónimo de libertad en el acto decisorio, significa para el nuevo paradigma la apremiante busca por la legitimidad de las decisiones judiciales, habida cuenta de que no hay vinculación necesaria entre imprecisión lingüística y inexistencia de respuesta correcta. Esta no puede ser entendida como una mera consecuencia lógica de aquella, sino como una opción que la teoría (positivista) del Derecho toma para la solución del "problema". A partir de la teoría de la decisión dworkiniana, se construye una respuesta correcta no discrecional exigida por la noción de responsabilidad política del juzgador. Se entiende que la propuesta interpretativa de Ronald Dworkin puede ser erigida a un concepto general de Derecho como interpretación. A la coherencia con el pasado — el sistema legislativo y las decisiones judiciales— se suma la posibilidad de futura prórroga a casos similares, por lo que el principio que se extrae de la decisión debe también demostrarse como universalizable.

Palabras clave: Dworkin; teoría de la decisión; coherencia; integridad; responsabilidad política. 


\section{INTRODUCÃO}

A necessidade de elaborar uma teoria da decisão surge para o pós-positivismo como condição de sua existência. A indeterminação normativa, que, para o positivismo jurídico era sinônimo de liberdade no ato decisório, para Dworkin (2005) é vista no sentido de que "a imprecisão na linguagem jurídica consagrada não garante a indeterminação das proposições de Direito". Além disso, ressalta o autor, que as indeterminações "não significam que nossa pergunta não tem nenhuma resposta certa" (p. 190). Assim, significa para o novo paradigma a premente busca pela legitimidade das decisões judiciais, haja vista que não há vinculação necessária entre imprecisão linguística e inexistência de resposta correta. Esta não pode ser entendida como uma mera decorrência lógica daquela, mas sim como uma opção que a teoria (positivista) do Direito toma para solução do "problema".

Em meio a essa transição paradigmática, em que se pretende inumar o livre convencimento ao mesmo tempo em que se quer consagrar critérios que amarram o julgador ao dever de fundamentar suas decisões, a integridade e a coerência se apresentam como verdadeiros elementos da teoria da decisão judicial, razão pela qual se mostra necessário traçar as bases interpretativas do Direito que viabilizam uma decisão judicial fundamentada que atenda às exigências do pós-positivismol.

O objetivo deste ensaio é demonstrar, a partir da teoria da decisão dworkiniana, como se constrói uma resposta correta não discricionária. A decisão a ser descrita é a "que não está permeada de vícios ou de entendimentos egoísticos e casuísticos. Não é uma decisão positivista, pragmática, realista, ativista e passivista, ou que prioriza o convencionalismo, o direito natural ou o historicismo" (Schulze, 2012). Advirta-se, contudo, que Ronald Dworkin elaborou sua proposta de interpretação do Direito com os olhos nos direitos individuais. Mesmo assim, entende-se que suas lições podem ser erigidas a um conceito geral de Direito como interpretação, aplicável, por isso, também aos direitos de outras dimensões. Buscam-se no autor as exigências de que a decisão judicial esteja embasada em um argumento de princípio. Este argumento deve estar adequado à teoria do direito, bem como deve se mostrar apto justificá-la de modo coerente, como requer a integridade. Como se verá, "a integridade é um valor político fundamental da comunidade, enquanto a coerência aparece como uma especificação da integridade, uma forma de assegurar que a decisão, seja do juiz, seja do legislador, é a melhor possível" (Rodrigues, 2005, p. 48). Ainda mais, deve servir como a melhor justificativa para os direitos e o conjunto de princípios. À coerência

\footnotetext{
1 Entende-se que a questão central do texto extrapola o cenário jurídico nacional. Nada obstante, o direito brasileiro é uma amostra bastante elucidativa do início dessa transição paradigmática, que se pode notar a partir da leitura dos artigos 489 e 926 da Lei 13.105/15 (Código de Processo Civil), que trazem para o campo legislativo as preocupações desse novo paradigma.
} 
com o passado — o sistema legislativo e as decisões judiciais — se soma a possibilidade de futura extensão a casos semelhantes, motivo pelo qual o princípio que se extrai da decisão deve também ser demonstrado como universalizável. São esses os elementos da teoria da decisão.

\section{A RESPONSABILIDADE POLIITICA COMO FUNDAMENTO DA BUSCA PELAS RESPOSTAS CORRETAS}

No seio de sua crítica contra o positivismo, Ronald Dworkin desenvolve a doutrina da responsabilidade política dos magistrados, segundo a qual o poder político exercido nos casos concretos somente pode ser legitimado se encontrar justificativa na teoria política que fundamenta todas as demais decisões dos juízes. Essa ideia de "consistência articulada" proíbe, por exemplo, decisões que, embora pareçam adequadas ou justas quando alheias ao contexto, não se enquadram na teoria que serve de base para as outras decisões (Dworkin, 2010b, p. 137-138). Não existe, portanto, a possiblidade de se sustentar decisões discricionárias em casos difíceis — relembre-se a impossibilidade de cisão estrutural - e decisões conforme o Direito em casos fáceis, porque mesmo nos casos difíceis a necessidade de respeito à teoria que justifica o poder exige que o magistrado descubra² de forma construtiva os direitos que as pessoas têm.

Nada obstante, a tarefa não é imune a questionamentos:

Qualquer caso subsumido em garantias constitucionais "vagas", coloca duas questões: (1) Que decisão é exigida pela adesão estrita, isto é, fiel, ao texto da Constituição ou à intenção daqueles que o adotaram? (2) Que decisão é exigida por uma filosofia política que adota uma concepção estrita, isto é, estreita, dos direitos morais que os indivíduos têm contra a sociedade? (Dworkin, 2010b, p. 210)

É a partir dessa linha de raciocínio que o autor norte-americano desenvolve a tese dos direitos. Há uma obrigação imposta aos juízes de, mesmo diante da indeterminação textual, definirem quais são os direitos que as pessoas têm, sem que isso represente uma invenção de obrigações ou deveres de forma retroativa. Isso decorre do fato de as pessoas serem titulares do direito de obterem uma decisão judicial favorável ainda que a demonstração dos direitos que as pessoas têm seja controvertida e contrária à ideia de um procedimento mecânico para identificar os direitos nos casos difíceis (Dworkin, 2010b, p. 127). Principal crítico de Dworkin, H. L. A. Hart deixa expresso que a defesa que faz do poder discricionário do juiz é, de fato, a grande divergência em

2 A palavra "descobrir" é utilizada no sentido voltado ao mister eminentemente interpretativo do juiz, inerente ao próprio conceito que Dworkin atribui ao Direito (direito é interpretação), sem que tal descoberta possa significar que os direitos já estão pairando em algum lugar, prontos para serem atingidos pelo conhecimento do intérprete. Em várias passagens de sua obra, o autor tem o cuidado de afastar os inconvenientes resultantes da adoção da metafísica clássica, representada pelo já descrito pensamento objetivista. 
relação ao seu opositor, que sustenta a necessidade de o julgador encontrar sempre no direito os fundamentos para proferir suas decisões. Pode-se dizer que esse pilar do positivismo hartiano permanece intocável:

Apesar disso, haverá pontos em que o direito existente não consegue ditar qualquer decisão que seja correcta e, para decidir os casos em que tal ocorra, o juiz deve exercer os seus poderes de criação do direito. Mas não deve fazer isso de forma arbitrária: isto é, ele deve sempre ter certas razões gerais para justificar a sua decisão e deve agir como um legislador consciencioso agiria, decidindo de acordo com as suas próprias crenças e valores. Mas se ele satisfizer estas condições, tem o direito de observar padrões e razões para a decisão, que não são ditados pelo direito e podem diferir dos seguidos por outros juízes confrontados com casos difíceis semelhantes. (Hart, 2011, p. 336)

Para demonstrar como seria construída a decisão conforme a sua teoria, Dworkin criou a metáfora do juiz Hércules. Veja o significado da metáfora:

E é por isso mesmo que o Hércules de Dworkin não pode ser epitetado de 'invencionista' ou 'solipsista' (ou qualquer variação realista ou pragmatista). [...] a busca de respostas corretas em direito não pode sofrer críticas porque estaria assentado em um juiz que 'carregaria o mundo nas costas'. Ao contrário, pela simples razão de que a busca de respostas corretas é um remédio contra o cerne do modelo que, dialeticamente, engendrou-o: o positivismo e sua característica mais forte, a discricionariedade. (Streck, 2014a, p. 138)

Ao situá-lo na teoria política sobre a qual é erigido o sistema jurídico, menciona, inicialmente, que esse modelo de juiz aceita as regras jurídicas, bem como as leis que criam e extinguem direitos e deveres, além de observar as decisões judiciais anteriores. Na determinação daquilo a que as pessoas têm direito, eis o que Hércules deve fazer:

[...] Hércules deve perguntar-se qual sistema de princípios foi estabelecido. Em outras palavras, ele deve elaborar uma teoria constitucional; uma vez que ele é Hércules, podemos pressupor que seja capaz de desenvolver uma teoria política completa, que justifique a Constituição como um todo. Sem dúvida, deve ser um esquema que se ajuste às regras particulares dessa Constituição. (Dworkin, 2010b, p. 166)

Ronald Dworkin (2010b, p. 167) propõe, e para isso também se vale da metáfora de Hércules, a necessidade de construção de uma teoria constitucional que dê conta da globalidade do sistema de regras que se tornam coerentes a partir de um "conjunto complexo de princípios", aptos a justificar e a dar sentido às regras, sendo que o problema da indeterminabilidade é resolvido por princípios a que os tribunais recorrem para fundamentar suas decisões. Isso traz diversos questionamentos. Pergunta-se, por exemplo, se ao assim procederem os juízes estão apelando a regras jurídicas ou decidindo com base em suas consciências, bem como quais são os critérios que es tabelecem a validade dos argumentos adotados pelos magistrados e de que maneira 
eles se consolidam nas práticas judiciárias. Nesse ponto, uma explicação se faz necessária em razão de uma dúvida que pode surgir numa leitura apressada de Dworkin. Nessa passagem, não há uma confusão entre regras e princípios, mas o termo "regra" é utilizado, aparentemente, para denotar a juridicidade dos padrões entendidos como princípios, em oposição ao que se verificaria se os juízes julgassem conforme sua consciência. Oportuna a lição de Rafael Tomaz de Oliveira (2008, p. 196):

Por outro lado, não temos em Dworkin a referência ao conceito de norma como gênero que comporta regras e princípio. Isso é assim porque — segundo Esser- os anglo-saxões não conhecem o conceito continental de norma, no sentido que lhe dá o idealismo normativista kelseniano. Entre eles, o conceito de norma corresponde ao conceito de regra (rule) e por esse motivo o conteúdo deôntico dos princípios não são atribuídos a partir de uma simples "normatividade" ainda prisioneira de uma teoria do conhecimento subjetivista. [...] se Dworkin não define princípio como norma —pois o conceito de norma é equivalente ao de regra - então como é possível afirmá-los deonticamente? [...] isso porque, a partir de Dworkin, poderíamos afirmar que essa dimensão deôntica que reveste as regras e os princípios é sempre interpretação, uma vez que, para ele, o próprio direito é interpretação, podemos dizer que norma não é um esquema de interpretação ou um conceito semântico que coloca entre parênteses a atividade judicativa que caracteriza o direito, mas sim ela própria já é interpretação.

Para o jusfilósofo americano, "os juristas e os leigos que fazem tais perguntas não o fazem a esmo e nem os move uma curiosidade vã; eles sabem que os juízes detêm um grande poder político e estão preocupados em saber se esse poder é justificado, seja em geral ou em casos particulares" (Dworkin, 2010b, p. 8). O autor prossegue indagando qual "justificação suplementar é exigida por esses casos difíceis" e lança as consequências que isso representa para o jurisdicionado, bem como aponta a insuficiência das teorias semânticas para solucionar o problema que se apresenta. Vejam as palavras do autor:

A questão da justificação tem ramificações importantes, pois afeta não somente a extensão da autoridade judicial, mas remete também à extensão da obrigação moral e política do indivíduo de obedecer à lei criada pelo juiz. Afeta igualmente os fundamentos com base nos quais se pode contestar uma decisão controversa. Se faz sentido afirmar que um juiz deve seguir os padrões existentes nos casos difíceis, então faz sentido para um objetor de consciência argumentar que o juiz comete um erro jurídico ao considerar constitucional o serviço militar obrigatório. Mas se os juízes somente podem criar novas leis nos casos difíceis, essa alegação é destituída de sentido. Portanto, embora a questão de se os juízes seguem regras possa parecer lingüística, na verdade ela revela preocupaçôes que em última instância são práticas. [...] existem controvérsias relativas a princípios que subjazem a um problema aparentemente linguístico. (Dworkin, 2010b, p. 9, grifo nosso)

Desde o início, o autor deixa claro que a indeterminação não pode ser resolvida com conceitos determinados de antemão. Não se está dizendo que os significados 
das palavras não sejam relevantes para a interpretação. Os sentidos, como se viu, são parte do processo, inadmitindo-se, a partir da ruptura paradigmática ocorrida com a invasão da filosofia pela linguagem, uma livre atribuição de sentidos no modelo determinado pela intersubjetividade. Contudo, a norma não resulta dos significados das palavras em conjunto, mas sim do sentido que lhe dá a coerência exigida pelo Direito como integridade. Ora, se "o texto jurídico nada diz, ou se as palavras estão sujeitas a interpretações conflitantes, então é correto perguntar qual das duas decisões possíveis no caso melhor se ajusta aos direitos morais de fundo das partes" (Dworkin, 2005, p. 15). De maneira ainda mais específica, Dworkin (2005, p. 189) afasta a inexistência de resposta correta nos casos em que a linguagem se afigura imprecisa e recorre aos princípios e à interpretação para determinar o conteúdo específico para o caso concreto. Na linha de sua teoria, delineadas a responsabilidade política dos juízes e a tese dos direitos, quer-se demonstrar, agora, que os juízes devem seguir os padrões existentes para construir suas decisões.

\section{A CONCEPCÃO INTERPRETATIVISTA DO DIREITO COMO INTEGRIDADE}

O Direito como integridade surge como teoria política e da Constituição. Dworkin o apresenta como decorrência de uma comunidade que adota o modelo de princípios ${ }^{3}$, o que significa dizer que as pessoas entendem não ser governadas apenas por regras decorrentes das convenções políticas, pois reconhecem a validade superior de um sistema de princípios atinentes à justiça, à equidade e ao devido processo legal cujo conteúdo faz parte da arena política. Por isso, "segundo o direito como integridade, as proposições jurídicas são verdadeiras se constam, ou se derivam, dos princípios de justiça, eqüidade e devido processo legal que oferecem a melhor interpretação construtiva da prática jurídica da comunidade" (Dworkin, 2014, p. 272). A sua legitimidade, em vez de se encontrar nas teorias contratualistas, está na ideia de fraternidade e de comunidade, bem como nas obrigações a elas referentes (Dworkin, 2014, p. 249-255). Ela representa, por isso, "a promessa de que o direito será escolhido, alterado, desenvolvido e interpretado de um modo global, fundado em princípios", caso em que se pode "sustentar a legitimidade de nossas instituições, e as obrigações políticas que elas pressupõem, com uma questão de fraternidade" (Dworkin, 2014, p. 258).

3 Esse é o terceiro modelo de comunidade apresentado pelo autor, que, no seu entender, obviamente endossado neste trabalho, supera o modelo de comunidade como um acidente de fato da história e da geografia, bem como o modelo de regras. Seus benefícios estão em especificar as obrigações dos cidadãos por meio dos princípios; impedir que qualquer pessoa seja excluída da política; representar uma exigência que demanda sacrifícios dos indivíduos; assegurar igual dignidade, de acordo com a definição coerente de seu sentido. Dworkin, R. (2014) O Império do Direito (3 ed.). (J. L. Camargo, Trad.). São Paulo: Martins Fontes. p. 257. 
A integridade é uma manifestação do pós-positivismo porque, a par de ser uma teoria interpretativa antidiscricionária, deixa evidente a superação dos demais pilares do positivismo em passagem que denota as alterações na teoria das fontes e da norma:

Se as pessoas aceitam que são governadas não apenas por regras explícitas, estabelecidas por decisões políticas tomadas no passado, mas por quaisquer outras regras que decorrem dos princípios que essas decisões pressupõem, então o conjunto de normas públicas reconhecidas pode expandir-se e contrair-se organicamente à medida que as pessoas se tornem mais sofisticadas em perceber $\mathrm{e}$ explorar aquilo que esses princípios exigem sob novas circunstâncias [...]. (Dworkin, 2014, p. 229)

A teoria dworkiniana é dividida em duas faces, haja vista suas implicações para a legislação e para a atividade jurisdicional. Sua principal função para o seu idealizador é como dimensão substantiva da argumentação jurídica que impulsiona o agir interpretativo em que se deve alcançar a melhor justificativa para o conjunto de proposições jurídicas cuja intenção seja a fundamentação de uma decisão de um caso concreto. Para Dworkin (2014), "se o direito é um conceito interpretativo, qualquer doutrina digna desse nome deve assentar sobre alguma concepção do que é interpretação" (p. 60). O autor se vale da íntima relação entre Direito e literatura para explicar sua proposta interpretativa. Busca-se a resposta correta da mesma maneira que se faz a interpretação textual e destaca-se como relevantes três características que devem ser absorvidas pela teoria jurídica. Primeiramente, a interpretação deve mostrar o texto como a melhor obra que ele pode ser; em segundo lugar, existe uma restrição severa que o texto implica ao intérprete, na medida em que a garantia de sua identidade exige que todas as palavras sejam levadas em consideração e não se admite mudanças textuais cujo objetivo seja deixar o texto melhor. Por fim, ainda quanto à identidade, a integridade não aceita que parte considerável do texto seja tratada como irrelevante ou desconexa, o que acarreta uma modificação no seu sentido (Dworkin, 2005, p. 223). Alerta o autor que "precisamos primeiro lembrar uma observação crucial de Gadamer, de que a interpretação deve pôr em prática uma intenção" (Dworkin, 2014, p. 67, grifo do texto original), que deve ser o relato do propósito de ver o texto em sua melhor leitura. Mostra-se com especial relevância o seguinte trecho, por sua relação com a hermenêutica filosófica e o afastamento em relação às propostas procedimentais:

Os juristas (como as outras pessoas) descobrem o alcance das reflexões que precisam fazer ao longo do processo de investigação, percebendo aonde esta irá levá-los antes de chegarem a uma posição de consenso. Eles não aceitam —não podem aceitar - uma metodologia que estipule de antemão onde devem parar, não importa quão inconcludente ou insatisfatória seja sua reflexão naquele momento. (Dworkin, 2010a, p. 100) 
Para julgamento da teoria que apresenta a melhor justificação, Dworkin oferece duas dimensões: a de adequação e da moralidade política. Para a primeira, uma teoria é a melhor justificativa porque quem dela se serve consegue embasamento e aplicação para suas proposições em maior escala do que suas rivais. Já a dimensão da moralidade política pretende obter uma justificativa melhor do ponto de vista dos direitos que as pessoas têm (Dworkin, 2005, p. 213).

No paralelo estabelecido com a literatura, na dimensão da adequação, um romancista, por exemplo, não deve endossar nenhuma interpretação de que, se adotada, não poderia resultar o texto escrito pelos demais autores. É necessário um poder explicativo geral (Dworkin, 2014, p. 277). Nesse sentido, a adequação se forma a partir de uma série de círculos concêntricos que giram em torno do caso que o juiz tem diante de si e concentram um conjunto de princípios que justifica, cada um desses círculos, uma determinada área do Direito e constitui aquilo que o autor chama de prioridade local, a partir da qual ocorre uma expansão para verificar se há uma justificação no plano mais geral proposto pela integridade ${ }^{4}$. Nesse ponto, Dworkin (2010a) introduz, em momento posterior, a ideia de ascensão justificadora, que funciona como uma espécie de teste a que se submete a interpretação para se alinhar à integridade da seguinte forma:

Nesse caso, qualquer argumento jurídico é vulnerável ao que poderíamos chamar de ascensão justificadora. Quando afastamos nosso olhar por um instante dos casos particulares que parecem mais pertinentes no momento e olhamos para as áreas adjacentes ao direito, ou, talvez, quando afastamos bastante nosso olhar e fazemos um exame geral [...] do direito constitucional ou dos nossos pressupostos sobre poder ou responsabilidade judicial —, podemos nos deparar com uma séria ameaça à nossa afirmação de que o princípio que estávamos prestes a endossar nos permite enxergar nossas práticas jurídicas sob a luz mais favorável. Isso porque podemos descobrir que esse princípio é incompatível ou não se harmoniza, em alguns outros sentidos, com outro princípio com o qual devemos contar para justificar alguma outra esfera mais ampla do direito. [....] Mas não podemos simplesmente ignorar a ameaça, pois o caráter do argumento interpretativo que estamos apresentando — e que devemos apresentar para sustentar uma alegação jurídica - confere relevância a qualquer ameaça desse tipo. (p. 76-77)

4 Dworkin, R. (2014). O Império do Direito (3 ed.). (J. L. Camargo, Trad.). São Paulo: Martins Fontes. p. 300-301. Na página 301, lê-se que "o direito como integridade tem uma atitude mais complexa com relação aos ramos do direito. Seu espírito geral os condena, pois o princípio adjudicativo de integridade pede que os juízes tornem a lei coerente como um todo, até onde lhes seja possível fazê-lo, e isso poderia ser mais bem-sucedido se ignorassem os limites acadêmicos e submetessem alguns segmentos do direito a uma reforma radical, tornando-os mais compatíveis em princípio com outros. Contudo, o direito como integridade é interpretativo, e a compartimentalização é uma característica da prática jurídica que nenhuma interpretação competente pode ignorar. Hércules responde a esses impulsos antagônicos procurando uma interpretação construtiva da compartimentalização. Tenta encontrar uma explicação da prática de dividir o direito em ramos diversos que mostre essa prática em sua melhor luz." 
A noção da ascensão justificadora, ainda que não seja indispensável em todos os casos, é, de fato, essencial para a realização do Direito como integridade, haja vista que propõe um necessário afastamento do caso concreto para que se verifique a adequação do princípio que se extrai da decisão particular ao conjunto de princípios que sustenta a comunidade jurídico-política. No caso brasileiro, em que se destaca a constante busca pela normatividade constitucional, o argumento viabiliza o controle efetivo de constitucionalidade a partir dos princípios constitucionais. Além disso, realça a importância da justificação e compatibilização da decisão diante da comunidade de princípios, o que se demonstra pela figura da "ameaça" na forma supracitada.

O todo deve ser explicado a partir da(s) parte(s) que, por sua vez, somente pode(m) fazer sentido a partir do todo. Não é acidental a relação da integridade com o círculo hermenêutico oriundo da filosofia hermenêutica. Nesse sentido, ensina Orlando Faccini Neto (2011) que "a melhor decisão, como se queira a resposta correta em Direito, é aquela em que se compreende o direito como integridade a partir dela - todo a partir da parte-, e que se insere, ou que se faz compreensível, em sua pertença ao todo do Direito — como parte do todo" (p. 63, grifo do texto original).

As convicções políticas que conformam a dimensão da adequação de que fala Dworkin não sustentam a discricionariedade judicial; de igual maneira, não são suficientes para afastá-la, como se fossem causas de um determinismo, razões que tornam inadequado considerar qualquer uma das duas alternativas a seguir, que, dependendo do ponto de vista acerca de quem determina quem, podem ser traduzidas pela seguinte questão: o juiz é quem forma as convicções pessoais que pretende fazer prevalecer nas decisões ou são as convicções que determinam sua voz nas decisões? A respeito, eis a explicação de Dworkin (2014):

Constitui uma parte conhecida de nossa experiência cognitiva o fato de algumas de nossas crenças e convicções operarem como elementos de comprovação ao decidirmos até que ponto podemos ou devemos aceitar ou produzir outras [...]. Poderíamos dizer que nesses exemplos a coerção é 'interior' ou 'subjetiva'. Ainda assim, é verdadeira do ponto de vista fenomenológico, razão pela qual é importante aqui. Estamos tentando ver o que é a interpretação do ponto de vista do intérprete, e, desse ponto de vista, a coerção que ele sente é tão genuína como se fosse incontroversa. (p. 282-283)

Quer-se dizer que cada uma das dimensões representa um embate com a discricionariedade em dois níveis diferentes. Na primeira, afastam-se as decisões que são inadequadas em relação à teoria mais geral que pode abranger o maior número de casos. Nesse nível, pode-se dizer que se eliminam as teorias que funcionariam como ameaça à autonomia do Direito. Na segunda dimensão, busca-se uma justificação mais 
específica acerca dos direitos e afasta se a discricionariedade pela fundamentação que consagra o Direito sob a sua melhor luz.

A dimensão da moralidade política pede o julgamento acerca de qual das interpretações que se ajustam à primeira apresenta o texto da melhor maneira, por se adequar a uma parte maior dele ou viabilizar uma integração mais interessante entre seus elementos (Dworkin, 2014, p. 278). Ao avançar na análise da segunda dimensão apresentada pelo autor, encontra-se uma nítida relação entre a tese dos direitos e a comunidade de princípios que sustentam o Direito. Encontrar os direitos que as pessoas têm a partir da interpretação construtiva impõe a consideração do todo para que a parte seja justificável como coerente, conforme ensina o autor:

A integridade, porém, é escarnecida não apenas em concessões específicas desse tipo, mas sempre que uma comunidade estabelece e aplica direitos diferentes, cada um dos quais coerente em si mesmo, mas que não podem ser defendidos em conjunto com expressão de uma série coerente de diferentes princípios de justiça, eqüidade, ou devido processo legal. (Dworkin, 2014, p. 223-224)

A exigência que a integridade impõe na determinação do conteúdo dos direitos fundamentais faz ainda mais sentido no ordenamento constitucional brasileiro, que demanda a necessidade de harmonizar dezenas de direitos individuais, sociais e transindividuais, cada um dos quais deverá ser defendido como expressão particularizada do conjunto de princípios constitucionais.

Escolher a interpretação que melhor se apresenta à luz da comunidade de princípios, quando se aceita o direito como integridade, na verdade não representa escolha alguma; é, sim, um dever de accountability imposto pela doutrina da responsabilidade política. São equivocadas, portanto, eventuais objeções à integridade que apontem discricionariedade — quer na formação da dimensão da adequação, quer na "escolha" da melhor interpretação. Impende registrar a maneira como Hércules encara a tarefa:

Assim, a escolha final de Hércules da interpretação que ele considera mais bem fundada em sua totalidade — mais eqüitativa e mais justa na correta relação— decorre de seu compromisso inicial com a integridade. Ele faz essa opção no momento e da maneira que a integridade tanto o permite quanto o exige, e, portanto, é totalmente enganoso dizer que ele abandonou o modelo da integridade exatamente nesse ponto. (Dworkin, 2014, p. 314)

Mesmo assim, prosseguirão os críticos sustentando que a melhor luz é subjetiva e, por isso, discricionária, como se existisse alguma relação de vinculação necessária. De forma brilhante, Dworkin (2014) antecipa-se à objeção com a seguinte resposta: 
A propósito de qualquer tese sobre a melhor maneira de avaliar uma situação jurídica em algum domínio do direito, eles dizem: "Essa é a sua opinião", o que é ao mesmo tempo verdadeiro e inútil. Ou perguntam: "Como você sabe?", ou "De onde provém essa pretensão?", exigindo não um caso que possam aceitar ou rejeitar, mas uma demonstração metafísica avassaladora à qual não possa resistir ninguém que a consiga compreender. E, quando percebem que não estão diante de nenhum argumento dotado de tal força, resmungam que a doutrina é tão-somente subjetiva. Depois, finalmente, voltam a seu ramerrão - fazer, aceitar, resistir e rejeitar argumentos da maneira de sempre, consultando, revisando e mobilizando convicções que lhes permitam decidir qual, dentre as avaliações conflitantes da situação jurídica, constitui a melhor defesa de tal posição. Meu conselho é direto: essa dança preliminar do ceticismo é tola e inútil; não acrescenta nada ao assunto em questão, e dele também nada subtrai. (p. 107, grifo nosso)

Por isso, ao apresentar argumentos que sustentam porque a interpretação de uma prática é melhor do que outra, Dworkin diz que está mesmo dando sua opinião, e não fazendo uma demonstração; convida, então, o leitor a apresentar os argumentos contrários para se chegar a um ponto de vista que se ajusta melhor as convicções que irão possibilitar a sua melhor avaliação. A resposta é —e isso não é uma fatalidade a se lamentar - subjetiva porque ela parte do sujeito; portanto, afasta-se da metafísica clássica, tendo em vista que não emana das coisas como se fosse da sua essência. Entretanto, subjetividade não quer dizer subjetivismo; o sujeito que decide é aquele do paradigma intersubjetivo, que presta contas na sua decisão e busca a legitimidade a partir da verdade, da substância. Exatamente por não se pretender encapsulado na formação de seu objeto de conhecimento, não confia no método capaz de proporcionar diferentes — senão antagônicos - resultados. Veja-se, portanto, por que não se pode duvidar da existência de respostas certas por não existir uma resposta que será aceita como correta por todos como se fosse possível uma demonstração absoluta de sua veracidade. Quem assim pensa necessita romper as amarras que o prendem às metafísicas. Isso não é o conceito de resposta certa para o pós-positivismo. De outro lado, a exigência de integridade promove a decisão não discricionária que pode ser a resposta correta se conseguir apresentar o Direito na sua melhor forma. Dito de outro modo, não é porque essa verdade irrecusável inexiste que a resposta correta é uma falácia.

Vê-se, portanto, que existem diversas questões que demandam respostas interpretativas para dar conta das exigências da integridade. Referindo-se a Hércules, Dworkin (2014) esclarece o significado dessas questões para a teoria da decisão:

Não devemos supor que suas respostas às várias questões que se lhe apresentam definem o direito como integridade como uma concepção geral do direito. São as respostas que, no momento, me parecem as melhores. Mas o direito como integridade consiste numa abordagem, em perguntas mais que em respostas, e outros juristas e juízes que o aceitam dariam respostas diferentes das dele às perguntas colocadas por essa concepção de direito. [...] Se você rejeitar esses pontos de vista distintos por considerá-los pobres enquanto interpretações construtivas da prática jurídica, não 
terá rejeitado o direito como integridade: pelo contrário, ter-se-á unido a sua causa.

(p. 287, grifo do texto original)

Ao introduzir as questões que pedem as respostas certas para o momento, Dworkin afasta-se dos anacrônicos juízos de fundamentação prévia e afina-se, ainda, à noção de temporalidade ou historicidade da compreensão, essencial à hermenêutica filosófica. Em respeito à integridade, deve o juiz avaliar se sua interpretação de parte do complexo de decisões e estruturas que formam o Direito de sua comunidade pode fazer parte de um todo coerente expresso pela teoria que o justifica (Dworkin, 2014, p. 294).

Assim, na medida em que busca explicar o todo, retoma-se a alegação da impossibilidade de cisão (metafísica) entre casos fáceis e difíceis. Ensina o jusfilósofo que "o direito como integridade explica e justifica tanto os casos fáceis quanto os difíceis", sendo que os "casos fáceis são apenas casos especiais de casos difíceis, e a reclamação do crítico é apenas aquilo que o próprio Hércules se daria por satisfeito em reconhecer: que não precisamos fazer perguntas quando já conhecemos as respostas" (Dworkin, 2014, p. 317). Mais uma vez, apresenta-se alinhado à hermenêutica filosófica, pois, no mesmo sentido, Gadamer (2015) diz que "a interpretação se torna necessária onde o sentido de um texto não se deixa compreender imediatamente. A interpretação se faz necessária sempre que não se quer confiar no que um fenômeno representa imediatamente" (p. 441).

Diante de tudo o que foi dito sobre o modelo de comunidade que a integridade quer justificar, o papel dos princípios é decisivo na transição paradigmática que perpassa este trabalho. Sua função reformula os três pilares positivistas, isto é, o reconhecimento dos princípios importa modificações na teoria das fontes, da norma e da interpretação. A lei não é a única fonte do Direito; o Direito não é um sistema composto somente por regras; e as decisões não mais são discricionárias quando as regras não são "suficientes", 5 não sendo legítimo ao juiz dar continuidade ao processo de criação das regras. Nesse sentido, Dworkin (2010b) argumenta que "o positivismo é um modelo de e para um sistema de regras e que sua noção central de um único teste fundamental para o direito nos força a ignorar os papéis importantes desempenhados pelos padrões que não são regras" (p. 36). Contrariamente à discricionariedade, o

5 A suficiência foi destacada em razão de apresentar, nesta frase, mais de um significado que se quer transmitir. Em primeiro lugar, como já se ressaltou, as regras não se sustentam nessa espécie de suficiência ôntica na qual aposta(va) o positivismo, como se a mera redação clara de uma regra fosse garantia de sua aplicação a partir de raciocínios silogísticos, o que é impedido em decorrência da antecipação de sentido que determina a compreensão, elemento inarredável de qualquer interpretação. Em segundo lugar, a insuficiência da regra também se verifica na impossibilidade de aplicá-la de forma dissociada dos princípios que contribuem para a sua normatividade, ou seja, o seu próprio sentido no caso concreto. 
autor enaltece a força dos princípios nos casos difíceis e a sua função essencial para que os magistrados, cientes da obrigatoriedade de respeitar os padrões, encontrem, a partir dessa prática interpretativa, os direitos e obrigações das partes nos casos controversos.

A objeção mais evidente que se pode apresentar é que os princípios não podem determinar o resultado da demanda judicial, ou seja, os defensores da discricionariedade sustentam que o recurso aos princípios não afasta o poder discricionário do juiz. Além de rebater o argumento no sentido de que seria apenas mais um modo de dizer que os princípios não são regras, Dworkin (2010b, p. 57, grifo do texto original) leciona que os princípios podem apontar a direção a ser seguida, que deve ser contraposta ao peso dos princípios que apontam para outra direção, sendo que esse "conjunto de princípios pode ditar um resultado."

Os princípios exercem função ímpar, à vista da tese dos direitos que Dworkin opõe ao positivismo, na determinação das obrigações jurídicas, o que se pode certamente aplicar para as obrigações do Poder Público em relação à coletividade, inclusive por meio de políticas públicas. Ensina o autor estadunidense que "uma obrigação jurídica existe sempre que as razões que sustentam a existência de tal obrigação, em termos de princípios jurídicos obrigatórios de diferentes tipos, são mais fortes do que as razões contra a existência dela." (Dworkin, 2010b, p. 71).

O autor reconhece, portanto, a dificuldade, senão a impossibilidade, de estabelecer um único sistema de princípios que dê conta de todas as normas e padrões que integram o ordenamento jurídico. Ainda assim, propõe que isso deva ser considerado como um defeito que exige empenho para remediar as incoerências interpretativas dos princípios (Dworkin, 2014, p. 261).

A decisão judicial fundamentada precisa respeitar toda a comunidade de princípios e regras que integram o ordenamento jurídico. Essa é uma das razões pelas quais a cisão estrutural entre regras e princípios, tantas vezes adotada nos casos concretos pelas Cortes brasileiras, impede que a facticidade seja efetivamente considerada no ato de julgar. Isso porque ora se sustenta nos raciocínios dedutivos, o que motiva a decisão judicial com a mera menção de um princípio, aplicado por subsunção, como se o princípio fosse uma pauta geral ou categoria - que funcionasse como premissa maior no silogismo - apta a abarcar toda a realidade e, por isso mesmo, destoada da concretude fática; ora se elegem dois princípios para legitimação da decisão pelo procedimento - a ponderação-, e olvida-se da necessidade de respeitar todo o conjunto de princípios e a sua relação com as regras aplicáveis aos casos, quando deveria prevalecer a interpretação que melhor promovesse essa unidade. 
A resposta correta não pode ser amarrada a dois princípios, menos ainda a um princípio, como se dá na decisão por subsunção. Vale dizer que, malgrado um problema interpretativo possa colocar em oposição evidente dois princípios que estariam a apontar decisões antagônicas, talvez a resposta seja dada pelos demais princípios, que, aplicados em conjunto, definem a solução que melhor representa a integridade. Dificilmente uma decisão pode ser acertada e, nesse mesmo sentido, fundamentada, se a comunidade de princípios e as regras forem deixadas de lado. É nesse sentido que "o homem que deve decidir uma questão vê-se, portanto, diante da exigência de avaliar todos esses princípios conflitantes e antagônicos que incidem sobre ela e chegar a um veredicto a partir desses princípios, em vez de identificar um dentre eles como válido" (Dworkin, 2010b, p. 114). Além disso, a cisão estrutural entre regras e princípios também acaba por afastar as regras (o que não vale para a regra da ponderação, evidentemente) dos casos difíceis, quando muitas vezes são indispensáveis para determinar o resultado, influenciando até mesmo na dimensão de peso, como se viu anteriormente. Todo caso, fácil ou difícil, é, ao menos de uma forma geral, uma questão de regras e princípios.

Por essas razões, os princípios representam o resgate do mundo fático na decisão judicial, e se corre o risco de perder essa importante função na teoria da decisão caso se abandone o sentido pragmático-problemático de princípio aqui endossado por um catálogo estanque de princípios epistemológicos ou pelos vetustos princípios gerais de Direito, mecanismos da matematizacão do paradigma positivista. Isso se percebe na teoria dworkiniana, sendo digno de nota, no seguinte exemplo:

Ela só sabe com quais problemas vai se deparar quando eles se apresentarem, e não tem como dizer, pelo menos até esse momento, se os problemas que inevitavelmente encontrará vão exigir que ela repense algum princípio [...]. repetindo, o que afirmo é que o raciocínio jurídico pressupõe um vasto campo de justificação, aí incluídos princípios bastante abstratos de moralidade política, que tendemos a dar essa estrutura por certa tanto quanto a engenheira o faz com a maior parte de seus conhecimentos, mas que podemos ser obrigados a reexaminar alguma parte da estrutura de vez em quando, embora nunca possamos ter certeza, de antemão, quando e como. ${ }^{6}$

E como identificar essa comunidade de princípios que a decisão deve respeitar? Existe a possibilidade de estabelecer um critério mecânico de identificação dos princípios, na linha da regra de reconhecimento de Hart? Seu crítico o responde:

6 Dworkin, R. (2010a). A Justiça de Toga (J. L. Camargo, Trad.). São Paulo: WMF Martins Fontes. p. 81. O autor se vale do exemplo da engenheira para demonstrar que, ao contrário de Hércules, capaz de construir toda a teoria completa do Direito para depois aplicá-la aos casos concretos, o intérprete comum pensa de dentro para fora, e nos casos concretos é que os princípios são (re)significados. 
É verdade que se fôssemos desafiados a sustentar nossa alegação de que determinado princípio é um princípio do direito, mencionaríamos qualquer um dos casos referidos anteriores, nos quais tal princípio fosse citado ou figurasse na argumentação. [...] qualquer lei que parecesse exemplificar esse princípio (melhor ainda se o princípio fosse citado no preâmbulo de uma lei, nos relatórios de comissões ou em outros documentos legislativos a ela associados). A menos que pudéssemos encontrar tal apoio institucional, provavelmente não conseguiríamos sustentar nosso argumento. [...] Ainda assim, não seriamos capazes de conceber uma fórmula qualquer para tentar quanto e que tipo de apoio institucional é necessário para transformar um princípio em princípio jurídico. [...] Argumentamos em favor de um princípio debatendo-nos com todo um conjunto de padrões —eles próprios os princípios e não regras - que estão em transformação, desenvolvimento e mútua intenção. Esses padrões dizem respeito à responsabilidade institucional, à interpretação das leis, à força persuasiva dos diferentes tipos de precedente, à relação de todos esses fatores com as práticas morais contemporâneas. E com um grande número de outros padrões do mesmo tipo. (Dworkin, 2010b, p. 64-65)

Se o Direito, para Dworkin, é interpretação, a identificação dos princípios não poderia escapar da prática interpretativa. Isso resulta em relativismo? Os princípios o são quando quer o intérprete e o seu padrão obrigatório é determinado conforme sua vontade?

Soma-se às respostas negativas às duas perguntas a concordância com Lenio Streck (2014b, p. 67) quando ensina que faz até mais sentido a teoria de Dworkin se adotada para o ordenamento brasileiro, em que os princípios constitucionais podem ser sustentados de modo ainda mais sólido do que os princípios de uma teoria da moralidade política que deva ser desenvolvida a partir de uma prática jurídica estabelecida, diante do menor grau de controvérsia existente. Tem-se, no Brasil, a vantagem do limite representado pelo texto e seu contexto. Ainda assim, é oportuna a menção à proposta de identificação segundo a qual "um princípio é um princípio de direito se figurar na mais bem fundada teoria do direito que possa servir como uma justificação das regras explícitas, tanto substantivas como institucionais, da jurisdição em questão" (Dworkin, 2010b, p. 105). Ao destacar-se o cenário jurídico brasileiro na forma que foi acima delineada, tratar-se-á de um princípio constitucional se fizer parte de sólida teoria da Constituição e puder, ao mesmo tempo, justificar as regras constitucionais explícitas.

Na linha do que foi dito, uma das decorrências do argumento segundo o qual a aplicação dos princípios, quando afastada a cisão estrutural, não prescinde das regras é a necessidade de controle na atribuição de sentido que o texto representa ao intérprete. Sobre isso, ensina o jusfilósofo:

Os termos da lei efetivamente promulgada pelo poder legislativo permitem que este processo de interpretação opere sem incorrer em qualquer absurdo; permitem 
que Hércules afirme que o poder legislativo estendeu uma política até os limites permitidos pela linguagem de que fez uso. No entanto, Hércules não supõe que o poder legislativo tenha estendido essa política até um ponto ulterior indeterminado, além desse limite. (Dworkin, 2010b, p. 171)

No que diz respeito à possibilidade de alteração de regras por parte dos juízes, o autor também recorre a uma dupla função dos princípios para sustentar a atuação judicial que promova a mudança. Em primeiro lugar, exige que a atitude favoreça um princípio, embora entenda que isso não seja suficiente. Quanto à outra função, transcreve-se a sua lição:

[...] um juiz que se propõe a modificar uma doutrina existente deve levar em consideração alguns padrões importantes que se opõem ao abandono da doutrina estabelecida; esses padrões são, na sua maior parte, princípios. [...] As doutrinas da supremacia do Poder Legislativo e do precedente inclinam em favor do status quo, cada uma delas na sua própria esfera, mas não o impõe. Os juízes, no entanto, não têm liberdade para escolher entre os princípios e as políticas que constituem essas doutrinas - também neste caso, se eles fossem livres, nenhuma regra poderia ser considerada obrigatória. (Dworkin, 2010b, p. 60)

Portanto, a mudança de que fala Dworkin deve ser feita em nome da integridade e legitimar-se por sua intenção de corrigir um erro anterior, o que deve obrigatoriamente constar como justificativa da decisão. Essa mudança, evidentemente, não diz respeito à alteração de leis ou de textos de outras espécies normativas, mas de sua interpretação, bem como no que concerne a outros princípios e decisões judiciais, que servirão para justificar o Direito de forma coerente. Além disso, agrega-se à ideia de melhor justificação a exigência de que a aplicação do princípio demanda, em vez da ponderação, uma compatibilidade que deve ser buscada na interpretação do caso concreto, e salienta-se que "o princípio não deve estar em conflito com os outros princípios que devem ser pressupostos para justificar a regra que está aplicando ou com qualquer parte considerável das outras regras" (Dworkin, 2005, p. 15). O autor também apresenta o argumento como uma questão de coerência:

Um argumento de princípio pode oferecer uma justificação para uma decisão particular, segundo a doutrina da responsabilidade, somente se for possível mostrar que o princípio citado é compatível com decisões anteriores que não foram refeitas, e com decisões que a instituição está preparada para tomar em circunstâncias hipotéticas. [...] Coerência aqui significa, por certo, coerência na aplicação do princípio que se tomou por base, e não apenas na aplicação da regra específica anunciada em nome desse princípio. (Dworkin, 2010b, p. 138-139)

Conclui-se a partir dos últimos argumentos que, embora um princípio possa se apresentar como justificativa de uma decisão, a resposta somente será correta quando o seu sentido surgir da interpretação conjunta com os demais princípios que 
convivem na mesma teoria do Direito, sendo imprescindível que a significação leve a sério as regras aplicáveis. Nessa linha, Dworkin (2005) adverte que "o legislativo endossa princípios aprovando a legislação que esses princípios justificam. O espírito da democracia é aplicado quando se respeitam esses princípios" (p. 24). Aplicar a lei é, em vez de uma atitude positivista, um fiel compromisso com a democracia, que não deve ser desfeito sem sólida justificativa.

Impende registrar que, se as regras sempre têm um princípio que as institui ou lhes confere sentido concretamente, também os princípios têm seu alcance muitas vezes determinado pelas regras, sem que com a constatação se defenda uma interpretação da Constituição conforme a legislação. É claro que o ponto de vista é o inverso. Nada obstante, as regras não podem ser esquecidas como se perdessem importância diante da relevância e da constitucionalização dos princípios. Vale ressaltar que ambas as espécies normativas podem ter assento constitucional, o que sinaliza a possibilidade de que a dimensão de peso varie em função das regras com base no caso concreto.

\section{A COERÊNCIA COMO EXIGÊNCIA E TESTE DA INTEGRIDADE}

A questão do fundamento da decisão ganha outro contorno quando a justificativa se encontra em uma decisão judicial anterior. Antes de se ver como isso ocorre, cabe tecer algumas considerações sobre a possiblidade de aplicação da coerência dworkiniana e o sistema de civil law brasileiro. Há como se sustentar a vinculação dos juízes aos precedentes no Brasil? E se os precedentes integram, muitas vezes, a fundamentação das decisões, isso é opcional? Pode o juiz escolher a(s) linha(s) jurisprudencial(is) para embasar sua "convicção"? Ou existe algum princípio que justifique a teoria constitucional que exija uma aplicação coerente do Direito pelos tribunais? Talvez a palavra vinculação não dê a resposta certa aos questionamentos. Certamente, caso se sustentasse uma vinculação, as objeções apontariam que os juízes somente estão vinculados, no sentido de que devem obediência a determinadas decisões, aos julgados em sede de controle concentrado ou "abstrato" de constitucionalidade e às súmulas vinculantes. ${ }^{7}$ Nem por isso os juízes que não observam os precedentes "não vinculantes" deixam de cometer um erro, ao menos em potencial. Em primeiro lugar, há que se afastar a possibilidade de escolha do posicionamento jurisprudencial, tendo em vista que a decisão, como se viu, não é ato de vontade do julgador. A justificação da decisão que leva em conta os julgados anteriores é uma exigência do princípio da igualdade. Também o juiz Hércules chegaria a essa conclusão, que se completa com o argumento de princípio:

A força gravitacional de um precedente pode ser explicada por um apelo, não à sabedoria da implementação de leis promulgadas, mas à eqüidade que está em tratar os casos semelhantes do mesmo modo. Um precedente é um relato de uma decisão

Conforme dispõem os artigos 102, §2 , e 103-A da Constituição da República Federativa do Brasil. 
política anterior; o próprio fato dessa decisão, enquanto fragmento da história política, oferece alguma razão para se decidir outros casos de maneira similar no futuro. [...] Hércules concluirá que sua doutrina da eqüidade oferece a única explicação adequada da prática do precedente em sua totalidade. Extrairá algumas outras conclusões sobre suas próprias responsabilidades quando da decisão de casos difíceis. A mais importante delas determina que ele deve limitar a força gravitacional das decisões anteriores à extensão dos argumentos de princípio necessários para justificar tais decisões. Se se considerasse que uma decisão anterior estivesse totalmente justificada por algum argumento de política, ela não teria força gravitacional alguma. (Dworkin, 2010b, p. 176-177)

Espera-se que a prestação jurisdicional coerente não seja aleatória, devendo preservar e promover uma aplicação equânime do Direito, e o Estado-juiz não pode fazer distinções arbitrárias entre os jurisdicionados. Esse ideal, contudo, não é alcançado somente por meio de uma vinculação dos precedentes, no sentido de uma obediência cega ao que foi decidido. Isso porque a integridade pode exigir julgamento diferente para que a comunidade de princípios seja respeitada. Por isso é que deve integrar à teoria do precedente uma teoria do erro que permita, de modo limitado, contrariar algum julgamento anterior desde que se faça de forma justificada em princípios e demonstre-se as razões pelas quais a decisão melhor promove o conjunto de princípios nos quais a comunidade se assenta, o que envolve as hipóteses de que alguns princípios tenham sido negligenciados ou a eles tenha sido atribuído maior ou menor peso. Disso decorre, portanto, a desconsideração de parte da história institucional, que será tida como equivocada diante da impossibilidade de se obter uma total consistência, a que se soma a necessidade de identificar as consequências de se afastar da parte da história diante dos novos argumentos (Dworkin, 2010b, p. 186-189). Pode-se dizer, portanto, que se a igualdade propõe que, em princípio, as decisões judiciais devam ser aplicadas de forma coerente, a integridade, que não se resume à coerência, pode exigir uma decisão destoante das anteriores, seja em virtude daquilo que se denominou força gravitacional do precedente, seja porque a comunidade de princípios impõe, à luz da teoria do erro, uma nova interpretação.

Embora a coerência seja introduzida pelo autor no raciocínio jurídico a partir do estabelecimento de uma relação entre Direito e literatura, Dworkin (2005, p. 211) deixa claro que a coerência normativa é mais complexa do que a exigida por uma narrativa literária, malgrado isso não impeça a comparação de justificar a razoabilidade da existência de uma resposta correta para as demandas judiciais. O autor apresenta o paralelo com a imagem de um grupo de romancistas que seja contratado para escrever um único romance em cadeia, sendo que cada um deve escrever um capítulo em sequência e está ciente da dupla responsabilidade de interpretar e criar um texto único e integrado (Dworkin, 2005, p. 235-237). Eis a semelhança com a tarefa dos juízes: 
Decidir casos controversos no Direito é mais ou menos como esse estranho exercício literário. [...] Cada juiz, então, é como um romancista na corrente. Ele deve ler tudo o que outros juízes escreveram no passado, não apenas para descobrir o que disseram, ou seu estado de espírito quando o disseram, mas para chegar a uma opinião sobre o que esses juízes fizeram coletivamente, da maneira como cada um de nossos romancistas formou uma opinião sobre o romance coletivo escrito até então. [...] Ao decidir o novo caso, cada juiz deve considerar-se como parceiro de um complexo empreendimento em cadeia, do qual essas inúmeras decisões, estruturas, convenções e práticas são a história; é seu trabalho continuar essa história no futuro por meio do que ele faz agora. Ele deve interpretar o que aconteceu antes porque tem a responsabilidade de levar adiante a incumbência que tem em mãos e não partir em alguma nova direção. (Dworkin, 2005, p. 237-238, grifos do texto original)

O juiz fica, por isso, limitado à história institucional que tem diante de si, não podendo inventar uma história melhor, ao que se somam as restrições decorrentes das dimensões de ajuste e, num momento seguinte, chega ao resultado com esteio em teorias políticas substantivas (Dworkin, 2005, p. 240-241). As exigências da integridade são semelhantes àquilo que a coerência requer, contudo, a teoria do erro pede que se mantenha uma diferenciação para que se conservem como elementos distintos da teoria da decisão (Dworkin, 2014, p. 263-264).

\section{CONCLUSÕES}

Se o Direito, como propõe Ronald Dworkin, é interpretação, e este traduz-se num dos principais problemas jurídicos da atualidade, a interpretação, por sua vez, não deve ser sinônimo de discricionariedade, arbitrariedade, vontade e livre convicção do juiz.

O Direito, a partir do paradigma pós-positivista e do Estado Democrático, é a constante busca pela legitimidade, que passa pela construção de uma teoria da decisão que supere a discricionariedade em que se sustentava o juspositivismo. Como se viu, o conceito interpretativo que corresponde à visão dworkiniana do Direito é compatível com o dever inscrito no art. 93, IX, da Constituição da República, que decorre do direito fundamental à fundamentação das decisões judiciais. Contudo, o que se verifica a partir do estudo da teoria do jusfilósofo americano é que não só é compatível com o ordenamento jurídico pátrio como também se mostra necessário para explicar e resolver os problemas interpretativos que o Direito apresenta.

A adequada interpretação dos novos dispositivos legais, de que são exemplo o art. 489 e 926 do CPC, exige o respeito à coerência na forma do romance em cadeia, além de atender à integridade. Ao mesmo tempo em que se demonstra a adequação ao contexto jurisprudencial em que é produzida, a decisão precisa ser fruto das melhores justificativas do Direito como um todo observando-se a comunidade de princípios e regras de modo que seja factível a explicação dos fundamentos a partir da parte, 
mas que também deve encontrar o seu fundamento no todo, em uma compreensão circular que demonstre a realização da integridade.

\section{REFERENNCIAS}

Dworkin, R. (2005). Uma Questão de Princípio (2 ed.). (L. C. Borges, Trad.). São Paulo: Martins Fontes.

Dworkin, R. (2010a). A Justiça de Toga (J. L. Camargo, Trad.). São Paulo: WMF Martins Fontes.

Dworkin, R. (2010b). Levando os Direitos a Sério (3 ed.). (N. Boeira, Trad.). São Paulo: WMF Martins Fontes.

Dworkin, R. (2014). O Império do Direito (3 ed.). (J. L. Camargo, Trad.). São Paulo: Martins Fontes.

Faccini Neto, O. (2011). Elementos de uma Teoria da Decisão Judicial: hermenêutica, Constituição e respostas corretas em Direito. Porto Alegre: Livraria do Advogado.

Gadamer, H. (2015). Verdade e Método I: traços fundamentais de uma hermenêutica filosófica (15 ed.). (F. P. Meurer, Trad.). Petrópolis: Vozes.

Hart, H. L. A. (2011). O Conceito de Direito (6 ed.). (A. R. Mendes, Trad.). Fundação Calouste Gulbenkian: Lisboa.

Oliveira, R. T. (2008). Decisão Judicial e o Conceito de Princípio: a hermenêutica e a (in)determinação do Direito. Porto Alegre: Livraria do Advogado.

Rodrigues, S. M. (2005). A Interpretação Jurídica no Pensamento de Ronald Dworkin: uma abordagem. Coimbra: Almedina.

Schulze, C. J. (2012, dezembro). A Teoria da Decisão Judicial em Ronald Dworkin. Revista da AJURIS, 39(128).

Streck, L. L. (2014a). Lições de Crítica Hermenêutica do Direito. Porto Alegre: Livraria do Advogado.

Streck, L. L. (2014b). Verdade e Consenso: constituição, hermenêutica e teorias discursivas. (5 ed.). São Paulo: Saraiva. 